\title{
Peroxisomal Acyl-Coenzyme A Oxidase 2
}

National Cancer Institute

\section{Source}

National Cancer Institute. Peroxisomal Acyl-Coenzyme A Oxidase 2. NCI Thesaurus. Code $C 96443$.

Peroxisomal acyl-coenzyme A oxidase 2 ( $681 \mathrm{aa}, \sim 77 \mathrm{kDa}$ ) is encoded by the human ACOX2 gene. This protein is involved in the mediation of fatty acid oxidation and the synthesis of bile acid. 